\title{
Review on Major Protozoal Causes of Abortion in Cattle
}

\author{
Redi Argaw Mihretu Ayele \\ College of Veterinary Medicine and Agriculture, Haramaya University, P. O. Box 138, Dire Dawa, Ethiopia. \\ Addis Ababa University, College Of Veterinary Medicine and Agriculture, Department Of Microbiology, \\ Immunology and Veterinary Public Health Addis Ababa, Ethiopia \\ Mihretu Ayele* \\ Addis Ababa University, College Of Veterinary Medicine and Agriculture, Department Of Microbiology, \\ Immunology and Veterinary Public Health Addis Ababa, Ethiopia
}

\begin{abstract}
Summary
Neospora caninum was organism described as parasite of domestic dog. The tissues cysts seen in neural tissues. The disease can be transmitted by vertical and horizontal. Trans-placental infected pubis: the typical presentation is a flaccid and hind limb paresis Neospora abortion tends to peaks at mid gestation. Serological positive calves will ultimately give birth to calves that are infective and seronegative. Seropositive cow produce less milk than seronegative cows. Neosparn caninum was shown to use cattle as intermediate host and dog as definitive hosts. The most recommendation for prevention is try to prevent fecal contamination of feed and water on the dairy. Trichomonas fetus found in the vagina, uterus, macerated fetus, prepuce, epididymis and vasdeferense. Bovine trichomoniasis is venereal disease manifest in the cow and heifers by infertility, abortion up to $5^{\text {ts }}$ month after breading pyometra, and fetal mummification. Therefore, some of the common causes of abortion on cattle are discussed in detail in this review.
\end{abstract}

Keywords: abortion, cattle, trichomoniasis, diagnosis, neosporiasis

DOI: $10.7176 / \mathrm{JBAH} / 9-21-06$

Publication date: November $30^{\text {th }} 2019$

\section{Introduction}

Protozoal abortion has been recognized as a problem in the dairy herds of California since mid-1980s (Anderson et.al.. 1991) and around the same times protozoan parasite of dog was identified in Norway (Bjerkas et al., 1984). This was subsequently named Neospora caninum (Dubey et al., 1988). And the link was made to the infection of cattle (Thilsted and Dubey, 1989). Since then N.caninum has been identified as a cause of abortion in many part of world and major volume of research publications has been generated (Dubey, 1999) mode of infection (Anderson et al.. 2000). Seropositive animals are more likely their offspring without clinical sign (Anderrson, 1991; Dubey, 1999).

The most protozoal disease causing abortion in the cattle is N.eaninum and T.foetus which cause severe economic losses in the world wide (Dubey, 2003). Although horizontal transmission can introduce the disease in to naïve herd, vertical transmission is the most common. T. fetus is a venereal disease responsible for early embryonic death, infertility. Pyometra and abortion. It is particular problem in the range of cattle, where as many as $50 \%$ of herds may be infected (Dennet et al.. 1974). One review reported that death can occur at any time up to the fifth month of gestation (Yule et al.. 1989) and fetal infection also has been demonstrated in the abortion and in full term calves. No specific gross changes are seen in the aborted material. Histological examination reveals lesions of placentitis and pyogranulomatous, bronchopneumonia with evidence of tissue invention with the parasite (Rhyan et al.. 1999).

The objective of this paper is:

$>$ To determine the major protozoa causes of abortion in cattle.

\section{Review on major protozoal cause of abortion in cattle}

\subsection{Etiology}

The organism can be isolated with Neospora caninum is a protozoal parasite of phylum apicomplexa, family sarcocytida and class coccidae. $N$. caninum primarily infects dog and cattle but also wide range and infects all the major domestic livestock species as well as companion animals and certain wild life species (Radostits et al., 2007). Dogs are the only known definitive hosts with cattle as the major intermediate animal hosts. Natural infection is infrequently reported in sheep, goats and deer (Dubey, 1999). N. caninum is sporadic cause of encephalomyelitis and myocarditis in several species but its importance is association with endemic and epidemic abortion in the cattle. It is now the most common diagnosis for abortion in cattle in most countries difficulty from infected calves (Miller, 2002) Trichomonas fetus, flagellate protozoa, is the cause of bulls breeds cattle although herd using semen from commercial artificial insemination study service as the exclusive source of semen are not risk, herds that use custom collected and frozen semen or natural services are at risk. The disease much more prevalent in a beef cattle 
but deserves mention to remind as that dairy cattle are susceptible (Rebhun, 1995). Trichomonas fetus is similar to but not the same as venereal organism in human called $\mathrm{T}$. vaginalis. The cattle organism lives in the microscope fold of skin that line to bull's penis and internal sheath. As the bull gets older this skin grows and fold more and more, creating additional place where the organism can thrive. Therefore, older bulls are more likely to become chronically infected with the "Trich" organism than younger bulls. In the cow or heifer, the organism lives in the cavity of vagina and uterus until her immunity system eventually destroys it. That destruction process (Immunity) may not occur for 3-20 weeks. (Rebhun, 1995).

\subsection{Morphology and Identification}

Tachyzoites of neosporosis measures $6 \times 2 \mu \mathrm{m}$ and usually located in the cytoplasm of cells. Tissue cysts are oval, $107 \mu \mathrm{m}$ long, have a thick wall (up to $4 \mu \mathrm{m}$ ) and are found only in neural tissues (Taylor et al, 2007).

The Trichomonas fetus is pear shaped approximately 20x10 $\mu \mathrm{m}$ and has nucleus and 4 flagella, each rising from basal body situated at the interior rounded end three of flagella are free anteriorly, while the $4^{\text {th }}$ extend backwards to form an undulating membrane along the length of the organism and then continuous posteriorly as a free flagellum. The axostyle, the hyaline rode with skeletal function, extends the length of cell and usually projects posteriorly (Urquhart et al, 1996).

\subsection{Pathogenesis}

The pathogenesis of neosporosis has predilection for fetal chorionic epithelium and placental blood vessels producing fetal vasculitis and inflammation. Degeneration of the chorioallantois and, wide spread necrosis in a placenta (Buxton et al., 1998). Tachyzoites penetrate host cell and located in the parasitophorous vascoule. They can be found in macrophages, monocytes, renal tubular cells and in the brain, cranial and spinal neural cells are infected. Cell death is by the active multiplication of tachyzoites (Radostits et al., 2007).

In Bull, Prepucial discharge associated with small nodules on the prepuce and penile membranes may develop shortly after infection. Thereafter there are no clinical sign s or lesion (Urquhart et al..., 1996). Infection on females causes cervicitis and endometritis leading infertility, abortion or pyometra. The inflammatory changes in the endometrial and cervix are relatively mild and no specific. There is copious mucopurulent discharge. The exudates continuous or intermittent their discharges and the number and activity of Trichomonas can vary considerably. Abortion may be occurring at any time but mainly in the first half of pregnancy. There are no specific fetal lesions, but large number of protozoa may be found in the fetal fluid and stomach. The placenta covered by white or yellowish flocculent exudates in small amounts, and thickening and hemorrhage without necrosis evident on the cotyledons. When if develops copious with watery exudates containing floccules which brownish and sticky and contain swarms of Trichomonas (Taylor et al., 2007).

\subsection{Epidemiology}

\subsubsection{Prevalence}

Prevalence of Neospora coninum was initially associated with abortion in the early 1990s in postured cattle in Australia and New Zealand as a major cause of abortion, in large dairies in southern California, and dairies in New Mexico. Since the abortion associated with Neospora caninum has been reported from many countries, and has worldwide occurrence (Radostits et al..2007). Abortion may be epizootic or sporadic. In epizootic abortion the number of cows aborting varies. It is usually between 5 and $10 \%$ of cows may abort within a short period. The period of abortion may be a few weeks to a few months. There is no major seasonal occurrence and abortion occurs in both beef and dairy cows (Radostits et al..2007). Sporadic abortions occur predominantly in cows that have been infected congenitally and seropositive cows have greater risk for repeat abortion (Radostits et al..2007). Seropositive in herds can be high, but varies widely. One study in herds reports with in herd sero-prevalence ranging from 7 to $70 \%$ (Thurmond et al., 1997). Sero-positive dams have a 3 to 7 fold higher risk of abortion than seronegative dams (Thurmond and Hiettla, 1997). The major intermediate hosts are; Cattle, sheep and goats: and the final host is dog (Urquhart et al., 1996). Neospora located in the blood of the host (Taylor et al., 2007).

Trichomoniasis is worldwide problem; however, prevalence has now decreased dramatically in areas where artificial insemination is widely practiced and in Britain, the disease now probably extinct (Urquhart et al., 1996).

\subsubsection{Transmission}

Neosporosis is two route of infection in cattle; these are ingestion of oocysts on the dog's contaminating feed of water and vertical transmission ((Dubey, 1999). Live born calves from congenitally infected cows are themselves congenitally infected and the infection is believed to persistent and lifelong. One study conducted on two dairies found $81 \%$ of seropositive cows gave birth to congenitally infected calves. Prevalence did not increase with a cow age on either diary and was stable through the study period. The probability of a calf being congenitally infected was not associated with a dam age, lactation number, history of abortion. Calf gender or length of gestation. Other studies have shown that this route of transmission is highly efficient resulting in infection of $50 \mathrm{hp}$ to $95 \%$ of the progeny seropositive dams (Readostits et al., 2007). 
Congenital infection can result in abortion, or the birth of a normal, infected calf at one pregnancy and abort in subsequent pregnancy (Thurnond et al., 1997). The occurrence of infection in the same herds can be associated with specific family lines (Bejorkman et al., 1996). Whereas vertical transmissions are the major route of infection that leads sporadic abortions in cattle associated with Neospora caninum. Epidemiological evidence suggests that postnatal infection is often the cause of outbreaks of abortion (Dubey, 1999). Farm dogs have been shown to have a higher sero-prevallence to N.caninum than urban dogs suggesting that the disease cycle between cattle and dogs in rural environment. The importance of postnatal infection versus vertical infection in the genesis of abortion may vary between countries associated with differences in management system (Radostits et al., 2007).

Transmissions of trichomoniasis are nearly always by breeding, heifers and cows become infected by breeding infected males. Herds usually become infected by introduction into the herd of infected females or on infected bulls or intercourse between animals within the herd and infected animals outside of a herd (Ribhu, 1995). Infection presumably occurs by rubbing off organs from the prepucial membrane (Bondurant, 1999). Unlike many other protozoan organisms, Trichomonas fetus is in capable of forming cysts and cannot survive outside the host from any length of time (Fermandez, 1989). Thus, direct venereal contact is necessary for transmission of the infection. Rarely, direct equipment along with unsanitary techniques for genital examination can be a possible means of transmission (Googer and skirrow, 1986).

\subsubsection{Risk Factor}

Outbreaks of abortion in Neosporosis is often appear to be point source of infection, the risk factor offer than probable mass exposure to infected dog feces, are not known. With suspect source of infection of disease in a dairy herds occurs as an epizootic, with multiple abortions occurring in one to two month period; severally autolytic fetuses are aborted in the $5^{\text {th }}-7^{\text {th }}$ month of pregnancy in most report but earlier abortions are recorded in the same, and agent has been associated with outbreaks. Endemic abortion is more likely associated with the presence of congenitally infected cattle in the herd which at high risk of aborting, particularly in the initial pregnancy and in the pregnancy during the first lactation (Hernandez et al., 2002). Cows that have aborted higher risk for abortion in the subsequent pregnancies, but the risk decrease with each subsequent pregnancy. The true frequency of repeated abortion is unknown because cow may be culled for abortion. It has postulated that immune suppression result from concurrent infection bovine viral diarrhea (BVD) may increase the risk for infection with $N$. caninum outbreak of abortion. Concurrent N.caninum and BVD infection in the some study. One study has found a significant association between abortion cow with antibody to both $N$. caninum and BVD (Bejorkman et al., 2000). Some factors that put a herds at risk for acquiring and maintaining trichomoniasis are natural service, using least or borrowed bulls, or introducing any "non-virgin" bulls into herds without prior testing and a large herd size (smaller herd size decrease exposure of potential) (http.//www.acces.edu/pub/doc/A/ANR/13331).

\section{Life cycle}

\section{Life cycle of $N$. caninum}

The life cycle of $N$. caninum includes intermediate and definitive hosts, and consists of sexual cycles only occurs in the definitive host. The asexual cycle occurs in the intermediate and definitive host. During life cycle of $N$. caninum identify the following stages; Oocyst, sporozoite, bradyzoites, tachyzoites, and tissue cyst.

\section{Sexual cycle}

A definitive host eats materials (aborted fetus, placenta or raw infected carcass) containing $N$. caninum tissue cysts and is infected with the parasite. Sexual multiplication takes place in the intestine of definitive host (http;//www.neosporosis).

\section{Asexual cycle}

Cattle graze on the pasture or eating food contaminated by infected dog feces ingests $N$. caninum oocyst. In the gut sporozoites are released from the oocyst and penetrate the epithelium of the small intestine. The sporozoites then enter different tissues but are mostly found in the reticuloendothelial system. Here they are further differentiating into tachyzoites. Tachyzoites are reproduce rapidly asexually and invade different tissues and in a pregnant animals. The fetus through the placenta with the onset of the bovine immune response. Tachyzoites revert to dormant bradyzoites with in the tissue cyst (found mainly in the neural tissue). During further pregnancies in infected animals bradyzoites are reactivated and differentiate into tachyzoites that invade the fetus through the placenta (http://wwww.neosporosis).

\section{Life cycle of trichomoniasis}

Bulls once infected, remain so permanently. The organism inhabits the prepucial cavity and transmission to the cow occurs during coitus, from vagina Trichomonas reach the uterus through the cervix to produce cow grade endometritis. Intermittently, organisms are flushed into the vagina, often two or three days before estrus (Urquhart et al., 1996). Infection usually followed by early abortion. The organism being found in the amniotic and allantoic fluid. Subsequently cows appear to self-cure and in most cases appear to develop sterile immunity (Taylor et al., 2007).

\section{Clinical Finding of Neosporosis}

Abortion is the only clinical sign observed in infected cow, fetus may be die inutero, be reabsorbed, be mummified, 
still born, born alive but diseased, or born clinically normal but chronically infected (Radostits et al., 2007). Cows that are infected have decreased milk production in the first lactation, producing approximately 1 liter less of milk/cows per day than uninfected cows, are prone to abort and have a higher risk of being culled from herd at an early age. In addition to occurrence of early abortion, the disease in the beef herd is associated with the birth of life born, premature, low birth weight calves, depending up on the degree of prematurity, this calf can be kept alive with intensive care during the neonatal period. Most congenitally infected calves are born alive without clinical sign. Congenital infection can occasionally be manifested with araxin loss of conscious proprioception, paralysis and other neurological deficits in the new born calf but the majority of congenitally infected calves are clinically normally and surprisingly epidemiological studies suggested that congenital infection does not necessarily have detrimental effect on calf health and survival (pare et al., 1996). The most clinical signs Neosporosis abortion, mummification, weak calves with ataxia, exophthalmia (Urquhart et al., 1996).

\subsubsection{The clinical sign of Trichomoniasis}

In the bull there are no clinical signs once the infection is established. In the cow early abortion is a characteristic feature although this is often undetected because of small size of the fetus and the case may present as one of an irregular estrus. Other clinical signs are those of purulent endometritis of closed pyometra and in this case the cows may become permanently sterile. On the uterine discharge, pyometra and early abortion. The cow usually recovers and generally became immune at least for that breeding season, after infection or abortion (Taylor et al., 2007).

Diagnosis

Serological examination is Indirect Antibody Fluorescent Test (IAFT) or by ELISA and there is a good agreement between the two tests. ELISA test based on recombinant protein have higher sensitivity and specificity than that based on whole tachyzoites lysets (Louie et al., 1997). The IFAT highly sensitive and specific for detection of maternal infection (Otter et al., 1997). One study compared IFAT titers in the maternal sera from 40 cows whose fetus had been examined for Neosporosis by immunohistochemistry, of the 22 confirmed cases, 21 cows had titers of greater than 1 in 640, whereas only one of18 negative cases had titer of this magnitude (Otter et al., 1997). Persistence of titers following infection is uncertain and they may fluctuate during pregnancy. Positive titer in a cow that has aborted indicates exposure but not causality. Recently, immunoglobulin G (IgG) avidity patterns have been used to determine the duration of infection (Bejorkman et al., 2005).

\subsubsection{Necropsy Finding}

Gross findings are of autolysis. The brain may be autolysed, should still be submitted for examination along with liver, heart, and placenta if available. Histological lesions are multifocal encephalitis, myocarditis and per portal hepatitis. Liver lesions are more prominent in epizootic abortion. Immunohistochemistry using anti-N.caninum can be used to diagnose Neosporosis (Anderson, 1996). Serum is used to identify tachyzoites in tissue and the brain is the organ with highest detection rate (Wouda et al., 1997).

Diagnosis of Neosporosis can be made from distinctive brain and heart lesion in aborted fetus or blood titer in cow (Urquhart et al., 1996). An enzyme linked immunosorbent assay (ELISA) techniques for detection of Neospora caninum or bovine Neospora isolates is also used as an effective method to identify Neospora in a fetal tissue and establish definitive diagnosis (Conrad et al., 1993). More over PCR.

\section{Diagnostic techniques of Trichomonas foetus:}

Identification of Agent: A tentative diagnosis of trichononiasis is based on clinical history, signs of early abortion, repeated returns to service of regular cycle confirmation depends on demonstration of organisms in placental fluid, stomach contents of aborted fetus, uterine washing, pyometra, discharge or vaginal mueus. Infected birds are the most reliable material for diagnosis either prepucial or vaginal washing of scrubbings (kittel et al..1998; Mukhufhin et al.. 2003).

Culture: here the organisms are too few to allow for direct detection and culture identification. Cultures should be prepared. Cultures of the organism are usually required because in most cases the number of organisms is not large enough to make a positive diagnosis by direct examination. (Eagleson et al..1992). Inoeulation of samples into should be done as soon as possible after collection. For samples collected by prepucial wash it is necessary to process the sample by centrifuging. The sediment is then examined inoculated into culture media. The quality of water used is important and an antifungal can be added to the media to control yeast growth (Eagle son et al., 1992).

PCR: Molecular based techniques that use PCR technology have exploited for identification of Trichomonas foetus (Home et al..1994). Development of PCR diagnostic test offer number of potential advantages including increased analytical sensitivity, faster diagnostic turnaround time and the fact that the organism in the collected sample are not required to be viable. Initial research (Felleion et al., 1998) demonstrated that DNA primers are capable of detecting very low number of parasites from the laboratory cultures of the organism with no prepuce material present. However in prepucial samples, higher number of parasites is required to yield appositive PCR result; this is most likely that the sensitivity of diagnostic test will be influenced by the efficiency of the extracting method the procedures to overcome contaminating inhibitors. Primers using differentiate different population of animals is needed. These primers produce amplification products from some closely related flagellates 
(Trichomonas, T.mobilansis and Trichomonads from a cat that are indistinguishable from thus T.foetus (Gookin et al, 2002). It is possible that some of this species are synonymous with T.foetus. Recent work has demonstrated that these primers can be used to differentiate between T.foetus and non T.foetus. Trichomonads sometimes found in prepucial samples (Bondurant et al., 1999). DNA based techniques have a potential as an initial or primary test (Compero et al., 2003).

Alternative Test: Mucus agglutination test: Mucus samples collected from cervical region of the vagina, preferably a few days after estrus. Antibodies appear in cervical mucus about 6 weeks after infection and persist for several months. Antibodies may also be found in prepuce secretion. The mucus agglutination test in most useful as a herd test. Being capable of detecting latent or recently cleared infection. It is specific and does not cross react with campylobacter fetus or brucella abortus, but lacks sensitivity (Rhyan et al., 1999).

Intradermal 'tricin' test: An intradermal test for diagnosis of bovine trichomoniasis has been reported (kerr, 1981). The ingestion site is in the skin of neck, similar to the site used for tuberculin test.

Immunohistochemistry of tissue:- There are no specific macroscopic or microscopic lesions in the aborted fetus, and identification of organisms is necessary for diagnosis. An immunohistochemical technique using monoclonal antibody $(\mathrm{MAb})$ to detect $\mathrm{T}$.foetus information fixed paraffin-embedded placenta and fetal lungs from bovine abortion (Rhyan et al., 1999).

\subsection{Economic Importance}

Economic importance is associated by the direct cost of abortion and the indirect cost associated with establishing the diagnosis and rebreeding of replacement costs. Seroposetive helfers have been reported to produce less milk than seronegative herd mates (Dubey, 1999). Loss of animal production due to thus disease can be major importance, primarily because of decreased milk production in aborting cows. The common sequel of infertility increases the period between lactation and in an infected herd the average inter calving period may be prolonged by several months. In addition to loss of milk production, there is loss of calve and interference with breeding program. This is a greatest importance in a beef herd, where the calves represent the sole source of income. A high incidence of temporary and permanent infertility in a heavy culling of a valuable cows and some death occurs as result of acute metritis following retention of placenta. Estimates of economic losses associated with epidemic abortion include US\$35 million per year in Califorina, a US\$85 per year to daily and AQ US\$25 beef cattle in Australia and NZ\$17.8 for the dairy industry in New Zealand (Radostits et al., 2007).

The economic impact of trichomoniasis is primarily due to three factors. Loss of calve crops due to early embryonic loss or abortion. Loss of income due to higher weaning weights resulting from delayed conception and late calving (since calves are born latter in the season and then sold at lighter weaning weight) and culling of open cows and infected bulls associated with replacing valuable breeding stock (http://www.access.edu/puds/docs/A/ANR/13331).

\subsection{Treatment}

There is no possible treatment that can be used to curtail an ongoing abortion epidemic and possible drug therapies are generally not considered an option because of likely unacceptable milk and meat residues (Kimisey et al., 1986).

\subsection{Control Strategies}

By using computerized models, economic losses where described in beef calf herds (kasware et al., 1992). The return of fixed assets as determined by subtracting variable costs from the annual income was reduced by endemic Neospora infection (Larson et al., 2004). Three control strategies; culling females that foil to calm, selling seropositive females and purchasing seronegative replacements and excluding daughters of seropositive dams was the only economically beneficial strategy (Larson et al., 2004).

The infection level in dairy herd with low postnatal infection and predominantly congenital transmission was also reduced by culling seropositive animals (Hall et al., 2005) nevertheless there is no guarantee of minimizing the risk of post natal infection and abortion storms by having "Neospora-sterile herd" epidemic situations caused by primarily neospora exposure are generally associated with high rate of abortion rates (Mcalister et al., 2000). Extreme strategies should be adapted in order to prevent horizontal-transmission, seronegative herd (Anderson et al., 2000; Thurmond and Hietal, 1997). Since many potential vectors or non-recognized host species could be involved in the life cycle of $\mathrm{N}$. caninum and no proven method are available to prevent post natal infection. Such strategies could be seemed difficult to perform under extensive management or in areas where definitive hosts are abundant, but could be done small herds confinement. Finally, Neospora-seropositive cow with genetic superiority can remain in the herds as embryo donors, and Neospora free embryos can be obtained by using embryo transfer technology (Baillargeon et al.,2001:Landman et al., 2002).

It has been demonstrated an inactivated vaccine can reduce abortion rates (Romero et al., 2004). In their study the pre vaccination infection status of the cattle and degree of exposure post vaccination to N. caninum where 
unknown; however, the incidence of Neospora abortion was $11.2 \%$ (49/438) in vaccinated animals and 20.8 $(91 / 438)$ in the placebo in recent work similar immune response (titers of specific antibodies and concentration of IFN.g) were observed in naturally infected heifers and heifer inoculated with killed whole N. caninum tachyzoites preparation during the second trimester of gestation (Moore et al., 2005). However, it is also known that inactivated preparations are unable to prevent vertical transmission in cattle (Andrianarivo et al., 2005).

Antibodies generated by natural infection cannot presently be differentiated from those induced by vaccination. Nevertheless, since maternal antibody disappear by 6 months in calves born to vaccinated heifers (Moore et al., 2005), test and cull strategy could be performed in replacement heifer before breeding and vaccination. Furthermore, every pregnant bovine (infected or none infected) could be vaccinated and its progeny tested serologically before colostrum intake or after 6 month of age to determinate its infection status. New vaccine with specific marker would be a useful tool for differentiating would be vaccinated from infected animals. Another desirable tool diagnostic technique to detect specific antibodies found only naturally infected animals should be found to naturally infected cattle independently whether is vaccinated or not. Artificial insemination (AI) from non-infected donors' entirely satisfactory method of control for trichomoniasis, when AI is not possible, vaccination can be used to control infection (Gookin et al., 2002).

To prevent a herd from becoming infected, the following procedures have to be considered: 1.Maintain a young bull battery. 2. Conduct fertility exam and culture all bulls before the breeding season. 3 . Purchase only virgin, yearling bulls. 4. Do not share or lease bulls. 5. Do not purchase older cows and add them to your herd. 6 . Cull open cows. 7. Maintain a defined breeding season to identify reproductive problems. 8. Pregnancy test all cows and heifers 120 days after the breeding season and cull open females. 9. Keep fences in good repair to keep your neighbor's herd out. 10. You may elect to vaccinate, but vaccine alone will not prevent the disease from getting into the herd Trichomoniasis is an economically significant disease. Preventing the introduction of the disease into your herd can be difficult if biosecurity protocols are not implemented and maintained. Once this disease is introduced into a herd, eliminating it may require significant changes in herd management procedures (http://edis.ifas.ufl.edu.).

\section{CONCLUSION AND RECOMMENDATION}

Protozoa are a group of microscopic single celled organisms. Most protozoa are free living but some are causing abortion in animal's are Trichomonas and Neospora. Trichomoniasis caused by T. fetus which is flagellate and pear shaped round end. The transmission is infected bulls to susceptible cow or vice versa. It cause in female cattle are cervicitis, endometritis, infertility, abortion and pyometra. There is no specific lesion but large number of protozoa found in fetal fluid and stomach. N. caninum is transmitted when water and feed contaminated by dog's feces, poor quality of AI and during obstetrical management. Chronically infected cow transmit Neospora infection. Vertically, they develop protective immune response, which contribute to disease control after exposure to Neospora oocystes. Culling of seropositive animals should be done only if external source of contamination by $\mathrm{N}$. oocystes are controlled and introduction of infected animals can be prevented. The disease has economic importance by direct and indirect effect. There is no effective treatment for the disease. Diagnosis is made by identification of agent by culture and PCR, also using alternative test.

Based on the above conclusion the following recommendations are forwarded:

- Technicians should use qualified artificial insemination kits

- Contamination of food and water by dog faces should be prevented by

- Culling of seropositive animals; during this time prevent external contamination and stop introduction of infected animals

- $\quad$ Dogs should be avoid from feeding of contaminated material

- Avoid borrowed bulls supply

- Use virgin bulls

\section{ACKNOWLEDGMENTS}

First I would like to express my advisor Dr. Beniam Tsegaye to intellectual guidance and devotion of time in rectifying this manuscript. Secondly, I would like to thank my family, financially helping to the paper completed.

\section{REFERENCES}

Anderson, M.L. Andrianarivo, A.J. and Conrad, P.A. (2000), Neosporosis in cattle, A Reprod Sci, 61:417-31.

Andrianarivo, AG,Anderson M.L. and Rowe J D. (2005). Parasitology research, Immunoresponse during pregnancy in heifers naturally infected with N.caninum with and without immunization, 96:24-31.

Ball, L., Dargatz, D.A., Cheney, J.M. and Mortimer, R.G. (1987). Control of venereal disease in infected herd.Vet.Clin. North, Am., 3:561-574.

Barling K.S., Lunt DK, and Snowden KF (2001). Association of serological status Neospora J.Am.Vet, Assoc $210: 1259$. 
Bjerkas I., Mohn, S.F. and presthus, J. (1984). Unidentified cyst forming sporozoan causing encephalomyelitis and myositis in dogs. Zeltschritt for parasite nkunde, 70:271-274.

Bjork man, Uggla A, and Fross fross lings (1996). Prevalence and transmission of N.caninum infection in dairy:J. Vet.Diag.invest. 208:1441.

Bon Durant R.M, Gajodhar A., Cnpero C.M. (1999). Preliminery characterization Of Trichomonas foetus like protozoan isolation from preputial smegma or vergin bulls bovine practice, 13:450-455.

BryanL.A. Combell J.R. and Gojadhar A.A.(1999). Effects of temrature on the survival of Trichomonas foetus in transport, diamonds and in pouch TM TF media. Veterinary research, 144:227-232.

Buxton, D., Caldow, G.L., Maley, S.W., Marcks, J. and Innes, E.A. (1998). Neosporosis and bovine abortion in Scotland, Veterinary record, 141:649-651.

Campero, CM,Moore D P, and Lagomarsino H, (2003). Serological status and Abortion rate in progeny obtained by natural service or embryo transfer from N.caninum seropositive cows. J.Vet.Med. 52:233-245.

Dennet, D.P., Reece, R.L., Barasa, J.O. and Johnson, R.H. (1974). Observation On the incidence and distribution of serotypes of Ttrichomonas in beef cattle in North Eastern Australia. Ausralian Veterinary Journal, 50:427431.

Dubey, J.P., Carpenter, J.L., Speer, C.A., Topper, M.J. and Uggle, A.(1988). Newly recognized fatal protozoal disease of dogs., Jornal Veterinary Medicine Association, 192:1269-1285.

Dubey, J.P. (1999). Neosporosis the first decade of research International for parasitology, 29:1485-1488.

Eagle some M.D and Garciam M.M.(1992). Microbial agents associated with bovine genital tract infections and semen part one, brucella, Ieptospira, veterinary bull 62:743-775.

Fermandez, CF,(1989). Survival of T.foetus in the environmental published data on file, csu trend sa 7:145-251.

Felleison R.S.J., Lamblet N., Bachmanm, P. Nicolet.J. Muller N. and Cottstein B.(1998). Ditaction of Tricomonas foetus by PCR and DNA enzymes immunoassay based on RNA gene unit sequence.J.Clinical microbiology, 36:513-519.

Goodger, W.J. and Skirrow, S (1986). Epidemiologic and economic analysis of an unusual long epizootic of trichomoniasis in a large Californian herds, J A N M A, 189:772-776.

Gook in.J.L., Bitrehever A.J., Breitschwerd E.B. and Heavy M.G. (2002). Single tube tested PCR ditection of Trichomonas foetus in feline feces.,Journal of clinical microbial, 14:4126-4130.

Gregory M.W., Ellis B. and Redwood D.W.(1990). Comparison of sampling methods for the detection of T.foetus.veternary research, 127:16.

Hall CA, Reichel MP, and Ellis JT.(2005) Neospora abortions in dairy cattle diagnosis, mode of transmission and control veterinary parasitology, 128:231-241.

Hernandez J.Risco C, and Donovan A, (2002): Exposure of Neospora caninum serostatus and milk production J.Am.vet, Assoc 221:1742.

Hobson JC, Duffield TF, and Kelton D,(2002). Neospora caninum J.Am. vet. Assoc 221:1160

Home S.Y. Conrad P.J.Lefebvre R.B., perez B. and Bon Durant R.H (1994): The ditaction of bovine trichomonisiasis with specific DNA probe and PCR amplification system Jornal of Clinical Microbiology, 32:98-104

Kasari T.R. Barling K,MCgrann JM.(1999): Estimated production and economic losses from neospora caninum infection in texas beef herd, 33:113-120.

Kerr W.R.(1981). Intradermal test in bovine trichomoniasis veterinary reaserch,56:303-305.

Kintel D.R.Compero C.Van Hoosear K.A.Rhyan J.C and Bon Durant R.H (1998). Comparison of diagnostic methods for detection of active infection with Trichomonas foetus in a beaf heifers Jornal of American Veterinary Medicine Association,213:519-522.

Kvasnicka, W.G.,Hall,M.,Hanks,D.,Ebel,E. and Kearley,B.(1996). Current concepts in control of bovine trichomoniasis. Compendium on continuingeducation. Food Animal Medicine and Management, 18:51055112.

Landman JK, Jillella D, O’Donnoghue PJ,and McGowan MR.(2002). Confirmation of the prevention of vertical transmission of N.caninum in cattle by the use of embryo transfer. Aust. Vet. J.80:502-503.

Larson RL, Hardin DK, and Pierce VL., (2004). Economic consideration for N.caninum induced abortions in endemically infected herds of a beef cattle journal of America vet medicine association; 11:597-1604.

Loui K, Sverlow KW,Barr BC,Anderson ML and Conrad (1997) clin diag. Lab immune, 4:692-699.

Mancebo. O.A, russon S.M., Carabajal L.L. and Manzon C.M. (1995). Persistence of Trichmonas foetus in naturally infected cows and heifer in Argentina veterinary parasitological. 59:7-11.

Mcallister M.,Bjorkman C, Andersen R, and Rogers D G (2000). Evidence of point-source to N.caninum and protective immunity in a herd of beef cows.Journal of America Veterinary Medicine Association 217:881887.

Miller C.M.D, Quinn, H.E, Windsor, P.A and J.T.(2002). Neospora caninum from cattle, aust.vet.J, 80:620-625. Moore D P, Leunda M R, and Zamorano P (2005): vet parasitology immune response to N.caninum in naturally 
infected heifers and heifers vaccinated with in activated antigen during the second trimester of gestation; 130:29-39.

Mukhuthi, N.Irons, P.C, Michel A. and petal F. (2003). Evaluation of PCR test for the diagnosis of Trichomonas foetus infection in bulls, effect of sample collection method, and storage and transport media on the test. Theriogen., 60, 1269-1278.

Otter, A.,Jeflkey, M.,Scholes,S.,Helmick,B.,Wilesmith,J.W. and Trees,A.J.(1997). Comparison of histology with maternal and fetal serology for the diagnosis of abortion due to bovine neosporosis. Veterinary Record, 141:487-489.

Pare J, Fecteau G, and Fortin M, (1996) sero epidemiologic study of Neospora Can. J.Vet Res 60:133.

Parkrer S, Campbell J.R, Ribble C. and Gajadhar A.A (1999). Comparison of two sampling tools for diagnosis of tritrichomonas foetus in bulls and clinical interpretation of culture of results: Journal of American Veterinary Medicine Association: 215, 231-235.

Radostits, O,T., Gay, C.C., Kenneth, W.Hin, Cheliff and Peter, D.Constable, (2007). Veterinary Medicine. Text book of. Disease of cattle, horse, sheep, pigs, goats, $10^{\text {th }}$ edition 1509-1512.

Rhyan J.C.Wilson KL. Wagner B.Anderson ML., Bonodurant RH, Burgess DE, Mutwiri GK and Cobeil LB.(1999). Demonstration of Trichomonas feotus in external genital and of specific antibody in prepeutial secretion of natural infected bull's, vet.pathology, 36:406-411.

Ribhun, W.C (1995): T.fetus cause of abortion. Disease of dairy cattle in U.S.A. P. 463.

Schonman, MM.Bon Durant, L.,A, vanHoosear K.B. altthere W and Kochuli.C,(1994). Comparison of sampling and culture method for the diagnosis of Trichomonas foetus infection inj bulls.Veterinary reaserch, 134:60622.

Taylor M.A, Marshal R.N. and, Stack M. (1994). Morphological differentiation of Trichomonas foetus from other protozoa of the bovine reproductive tract Br.vet.jornal, 150:72-80.

Taylor ma coop rl and wall rl (2007). Parasite of reproductive tract $3^{\text {rd }}$ ed,vet. Parasitol. Pp. 119-123.

Thumond, M.C., Hietala, S.K. and Blanchard, P.C. (1997). Herd based diagnosis of Neospora caninum-induced indemic and epidemic abortion in cows and evidence for congenital and postnatal transmission Jornal of veterinary diagnostic investigation, 9:44-49.

Urquhart, G.M., Armoar, J, Duncan, J.L., Dunn,A.M and Jennings F.W. (1996): veterinary parasitology, $2^{\text {nd }}$ ed, 210-245.

Wouda W,Dijkstra T,Kramer AMH and Van Maanen C, (1997). Vet. Obstetrics and genital disease (theriogenology) $2^{\text {nd }}$ ed. Pp. 107-134.

Yule, A, Skirrow, S.Z., and BonDurant, R.H. (1989). Bovine trichomoniasis. Parasitology tody, 5:373-377. 